\title{
IntiWear: acrylic glass as a solar energy concentrator for wearables
}

\begin{abstract}
Nowadays, battery life is one of the most challenges issues in the development of Wearable Technologies. However, the light exposure of our body extends the possibilities of solar energy harvesting on Wearables. We propose a novel approach to intertwine solar cells and materials for energy harvesting through clothing and accessories' surfaces for creating self-charging devices and power generation. This paper presents IntiWear: an approach for using dye-doped acrylic as a solar energy concentrator for Wearables. The material we use is Polymethyl methacrylate (PMMA or Acrylic Glass) that was doped dyed to concentrate energy. This material is commonly used for harvesting energy through furniture, windows and buildings' surfaces that are exposed to the sun. For the purposes of this project, these pieces are in direct contact to the solar cells to concentrate and harvest energy from the PMMA pieces. The solar cells are cut in triangle and square shapes, and attached to the side of the PMMA pieces in order to not totally expose the solar cell. IntiWear's design incorporate PMMA into fashion where the solar cells are hidden, each energy concentrator becomes a clothing adornment, and the shape and colors are customizable. This paper shows different tests of the PMMA doped dye and our circuit performance. It also describes the development of two applications: a solar coat as a power bank for charging Smartphones and a self-charging purse that lights up whenever it is opened. The aim of the project is to generate sustainable energy by the use of an alternative solution for solar cells in Wearables that is efficient, customizable and fashionable.
\end{abstract}

Keywords: solar energy, wearables, PMMA, solar energy concentrator, solar cell
Volume 4 Issue 5 - 2018

\author{
Katia Vega,' Eunice Villicana, ${ }^{2}$ Sthy Flores, ${ }^{2}$ \\ Julian Noel $^{2}$ \\ 'Department of Design, University of California, Davis, USA \\ ${ }^{2}$ Department of Energy, UTEC, Peru
}

Correspondence: Katia Vega, Department of Design, University of California, Davis, One Shields Avenue Davis CA 95616, USA,Tel + 530537 6107, Email kvegi@ucdavis.edu

Received: July 12, 2018 | Published: October 15, 2018

\section{Introduction}

Due to different factors such as the proximity to the body, access to the wearer's location and mobility, Wearable Technologies have been increasing the possibilities of sensing and reacting to biodata and our environment. Thus, in the last decade, we could see Wearables, not just in research laboratories, but also at the Marketplace with an expected 25 billion dollars of revenue by 2019. ${ }^{1}$ The new advances in technologies make Wearables become smaller, more powerful, more flexible and more accurate, nevertheless, the batteries have not had the same technological improvement. Their durability are still the main challenges that Wearables face., ${ }^{2,3}$

Wearables and energy technologies give a new dimension to self-sufficient devices. The aim of developing wearable designs that intertwine textiles, photovoltaics and energy storage to generate harvest energy is a leitmotiv to address voices to climate change and global warming. Energy demand is increasing at an impressive rate and harvest energy is a key player as energy derived from external sources at small amount can be used or stored for low energy devices. Using self-sufficient devices could reduce in a way the daily energy consumption of every individual on the earth and technology improvement on piezoelectric, sensors and materials for battery storage make harvest energy an asset for wearables.

In this field, the solar energy is the aplication most usual, particulary the photovoltaic has become more popular in the last years due to reducing of their costs maintaining or improving their efficiency. For it, an strategy is based on light concentrators, which are able to collect sunlight over large areas and redirect it onto small and efficient PV devices, increasing energy production and reducing the total cost of energy production. The most common and utilized concentrators are composed of mirrors and lenses that redirect sunlight exploiting geometrical optics. Even that this solution demonstrated an improvement in the technique, it requires to track the sun projection i.e. installation and maintenance of other sensor. An alternative to this approach is to concentrate sunlight by making use of dielectric slabs doped with fluorescent dyes. In these structures, sunlight is absorbed by the dyes and subsequently remitted at lower energies. Most of the re-emitted light is guided in the slab by total internal reflection and then converted to photocurrent by the PV cells attached to the lateral slab edges. Since the typical efficiency of luminescent solar concentrators is only a few percent, they are not yet able to compete with traditional concentrators for cost effective energy production. ${ }^{4}$ Some applications are made for building facades, windows and furniture that are exposed to radiation to harvest energy. ${ }^{5}$ Some of the commercial names for PMMA are Acrivill, Altuglas, Deglas, Limacryl, Lucite, Oroglas, Perclax, Perspex, Plexiglas, Plexiglass, Resartglass, Vitroflex, Trespex and Setacryl.

We present IntiWear (Figure 1), a wearable approach for harvesting solar energy by using Polymethyl Methacrylate (PMMA or Acrylic Glass) attached to solar cells. Our design promotes the use of different colors and shapes of the PMMA to serve as fashion accessories (Figure 1A \& 1B). The PMMA pieces concentrate energy coming from sunlight that is absorbed by the solar cells (Figure 1C). IntiWear uses the body surface as an energy collector due to its exposure to sunshine. The pieces are designed to be integrated in clothing and accessories as a fashion adornment (Figure 1D). Two applications show IntiWear possibilities. A coat that generates energy for charging a phone and a purse that operates without an external power source. 


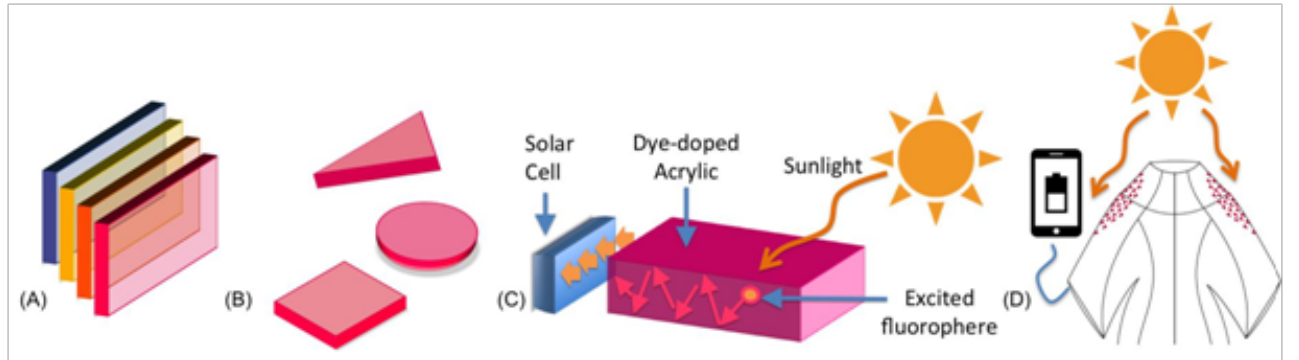

Figure I IntiWear.A) Polymethyl methacrylate (PMMA) in different colors. B) Different shapes to adapt the garment's design. C) PMMA as an energy concentrator with pv-cell. D) Functional garments for energy harvesting.

The following section outlines the motivation and background of the project. Section 3 presents the IntiWear's implementation in terms of design, PMMA characteristics and the circuit development. Section 4 shows the methodology for implementation os IntiWear and two applications and Section 5, the circuit and PMMA tests. Finally, Section 6 concludes the paper.

\section{Background}

Different sources are used for harvesting energy such as light (indoor and outdoor), ${ }^{6}$ mechanical energy (vibration), ${ }^{7}$ thermoelectric energy (Seebeck effect), ${ }^{8}$ electromagnetic waves (RF energy) ${ }^{9}$ but their small amount of production of energy is not sufficient to have an auto generated device; however, adds value to it, therefore, an energy storage device and a power control circuit is needed to optimize the charge of the device and ensure its operation.

Energy storage is well developed and vast for the electric grid; however, there are plenty of opportunities to improve energy storage for devices and increase their capacity. Electronics devices have dramatically increase over the last decade due the Internet of Things (IoT).$^{10-12}$ Most low-power devices are powered by batteries and their lifespan is limited. Thus, energy harvesting technologies provide a keen interest to IoT to be able to have unlimited operating low power devices. ${ }^{13-16}$ Also, the advantage of self-charging devices; generate new self-sustaining and cost effective devices ${ }^{17-20}$ as of today's energy harvesting devices have an energy storage system that buffer between the load and source.

Even though most Wearables use algorithms for controlling energy consumption and ultra-low power components, they regularly have to be electrically charged. Different sizes and shapes of lithium batteries are mainstream used for powering Wearables. And even now, flexible thin-film batteries are integrated into fashion as an alternative from the common rigid ones. ${ }^{21}$ The different modalities for energy harvesting that takes energy from external sources could also be applied to Wearables. For example, Seiko Thermic Watch ${ }^{22}$ uses the heat variation between the body and the ambient to generate the micro watts needed to make a mechanical movement of the clock. ETA Autoquartz Self-Winding Elect Watch captures energy from the vibration generated by a moving magnet. ${ }^{23}$ More extreme designs propose bio MEMs applications by the use of the blood pressure to power piezo electric system. ${ }^{24}$ Wearables and photovoltaic system cells have demonstrated the highest power density. ${ }^{25}$ Researchers developed several photovoltaic technologies for solar energy harvesting such as wearable fibre-shape polymers, ${ }^{26}$ photovoltaic textiles ${ }^{27}$ and stretchable polymers. ${ }^{28}$

Fashion technology had already proposed the use of harvesting energy into garments. Solar Shirt by Pauline Van Dongen presented 120 thin films solar in a shirt for charging a phone. ${ }^{29}$ The partnership between Pvilion and Tommy Hilfiger produced Solar Powered Jacket. It is a jacket with the back fully covered with flexible solar panels. ${ }^{30}$ Also, Yokoyama designed jewelry with solar cells ${ }^{31}$ in a shape of a big collar.

These prototypes presented flexible solar cells that could be integrated with clothing. However the solar cells are totally exposed. In the other hand, Landerer et al. created solar glasses with flexible and transparent solar cells $\mathrm{s}^{32}$ that the solar cell has the shape of a glass in order to hide the shape of the solar cell.

Wearables offer great advantages for both low-voltage and lowpower applications. However, to be able to optimize the wearable design, it is needed to realize reverse engineering, in this case knowing the load (cell phone battery was our starting point) to complete the design. The proposed solar energy harvesting system is composed of 3 main parts (Figure 2):

a. Transducer or harvesters, source of energy that is collected and then transformed/converted into electrical energy. In the case of IntiWear, we are using florescent cast acrylic and photovoltaic cells.

b. Power management and conversion circuit, this unit is the core of the system as it typically transforms the source of energy and then delivers it. Component of this unit include regulators and complex control circuits that can manage the power, all has to be low power consumption.

c. Energy storage and load, this is composed of battery or super capacitor depending of the application of the devices to be powered. Then, the energy is dissipated into the load; in this case the load is a cellphone.

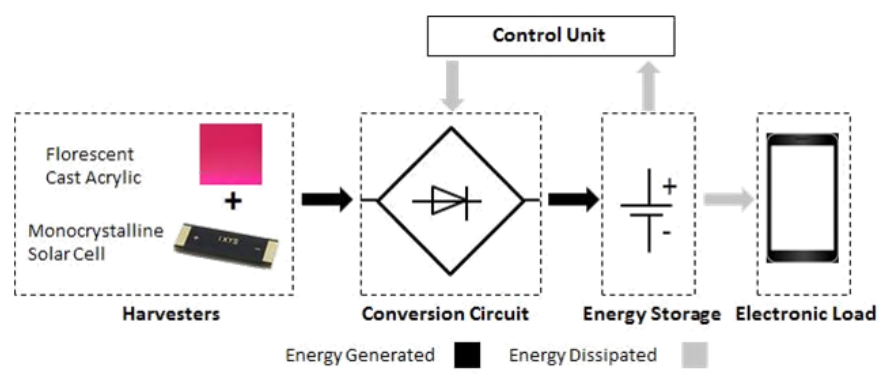

Figure 2 IntiWear concept design

\section{Transducer or harvesters}

The IntiWear harvesters are a sort of photovoltaic device based on luminescent concentrators (LC). This is a planar device make up of a luminescent polymer - generally polymethyl methacrylate (PMMA) doped with a fluorescent dye. When sunlight hits the 
LC a part of this come into the LC and is absorbed by the dye and then re-emitted as his fluorescent light in all directions - isotropic emission. The amount of light reflected, transmitted and refracted by the LC are quantize by the Snell law of the refraction and the Fresnel equation. Because of the $\mathrm{LC}$ has a refraction index bigger than the air, the critical angle of reflection exists only into the LC. It means, if a ray into the LC hits the LC surfaces at angles bigger than the critical angle it will be reflected entirely and remaining confined into the LC. After consecutives reflections the ray arrives to the edges where high efficiency photovoltaic cell convert light in electrical power (Figure 1C).

The most important issue in a planar LC is the doping dye. In the case of PMMA it is limited only to organic dyes because only those can be dissolved in PMMA. A dye for luminescent concentrators confers to the PMMA absorption and fluorescent properties. In fact, a dye for LC is characterized by its absorption and fluorescent spectra. The former defines the spectral range in which the dye absorbs sunlight and the latter in which the absorbed energy is re-emitted as fluorescence. In a ideal situation there is not overlaying between the spectra because this cancel the self-absorption of its own fluorescence. In real dyes the overlaying is present. It makes that a portion of the fluorescence to be re-absorbed by the same dye..$^{33,41}$ The dyes for LC cannot absorb the whole solar irradiance because a spectral windows is needed for the fluorescent emission. Otherwise the fluorescence would be reabsorbed suddenly. ${ }^{35}$ It is important consider that also the PMMA is an absorber in the IR and UV spectral ranges. Unfortunately, this absorbed light in not re-emitted as fluorescence but as heat.

\section{Luminescent concentrator of PMMA}

The PMMA is a material with great optical properties able to transmit the $92 \%$ of visible light and the $85 \%$ of the whole solar irradiance spectrum (power per unit area received from the Sun). With a refraction index of 1.49 and a negligible absorption in the visible, the $92 \%$ of transmitted light is due to the Fresnel reflection taking place in the both faces of a PMMA sheet. On the other hand, in some regions of the IR and IR the PMMA becomes an absorber. ${ }^{34,35}$ In this ensemble a portion of sunlight is absorbed by the dye and the reemitted as fluorescence into the luminescent concentrator. Because the fluorescence is generated into the LC (which is a medium with a refraction index higher than the air - the medium surrounding the $\mathrm{LC}$ ), this fluorescence is guided into the $\mathrm{LC}$ by total internal reflection forward the edges with pv-cells (Figure $1 \mathrm{C}$ ). ${ }^{36-38}$

\section{Conversion circuit}

In the IntiWear design, a piece of PMMA and a silicon cell are integrated in a small photovoltaic device that converts the solar radiation into electricity. This electrical current is not connected directly to the load (phones, tablets, and other wearable gadgets) but is storaged in batteries, this due to intermitence of solar radiation in a day. To storage energy from the photovoltaic system (harvesters) we need a unit control that regulate the voltage levels and to suministry the current out to battery. In this case, the control unit is TP4065, this is a device that generates of constant current and voltage linear charger for single cel lithium-ion batteries. This chip provides features to include a USB port to conduce the current out in DC. Has a programmable charge current us to $1000 \mathrm{~mA}$, preset 4.2V Charge Voltage with $1.5 \%$ accuracy (Figure 3).

Also, includes a current monitor, under voltage lockout, automatic recharge and status pin to indicate charge termination The common applications are in cellular phones, PDA's, GPS, USB Bus-Powered
Chargers, etc. ${ }^{39}$ This chip is integrated in a circuit with other LED indicators, USB port (in / out) and resistors, this requires that the voltage increase to $4.5 \mathrm{~V}$.

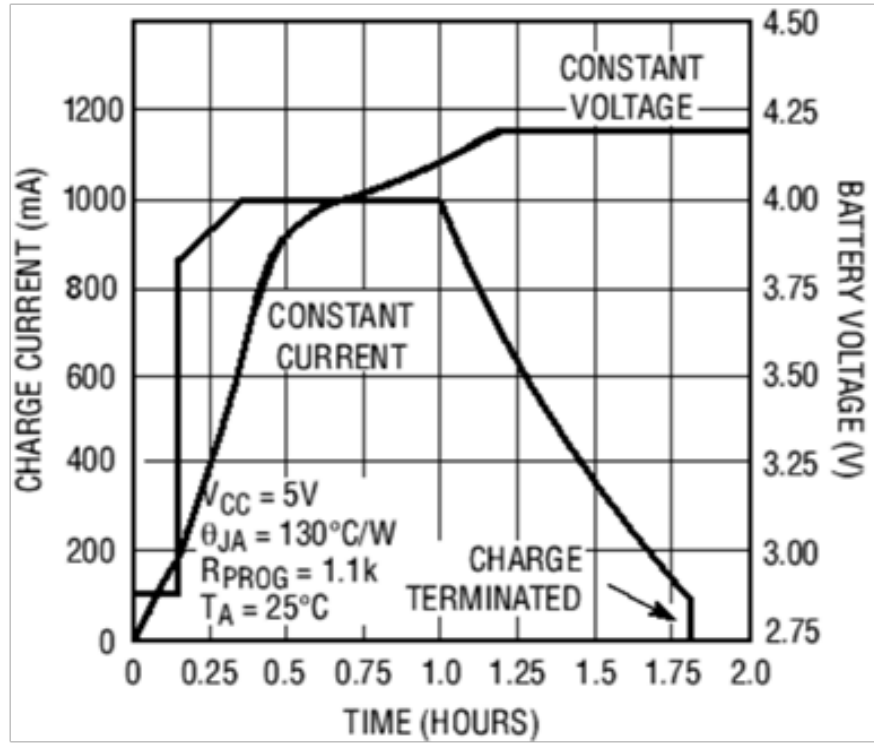

Figure 3 Complete Charge cycle of $1000 \mathrm{~mA}$ battery.

\section{Energy storage}

Generally wearable electronic devices work with direct current voltages of $3.7 \mathrm{~V}$. With respect the current level $(\mathrm{mA})$ storage, this depends of the load application; commonly $500 \mathrm{~mA}, 1000 \mathrm{~mA}, 2800 \mathrm{~mA}$ and recently $5000 \mathrm{~mA}$. In this case, we need to produce energy to store in a $1000 \mathrm{~mA}$ battery at $3.7 \mathrm{~V}$, the battery should be high energy density lithium polymer, with a long life cycle of charging and discharging more of 400 cycles. In this case, the battery is CL523450 with 500 cycles. Their dimension is $68 \mathrm{~mm} \times 44 \mathrm{~mm} \times 3 \mathrm{~mm} .{ }^{40}$ This dimensions are good for to encapsulate the control unit and the storage in a small box.

With this battery capacity, we can supply $35 \%$ of the total charge required by a standard smartphone. Considering these conditions, is necessary a power photovoltaic system of $5.8 \mathrm{~W}$

The energy generated by the solar PV system is sent to the control unit (charger), which is formed by the TP4056 module. This module requires a voltage in of $4.5 \mathrm{~V}$ to charge the battery. The battery is a LiPo of $1000 \mathrm{~mA}$ and $3.7 \mathrm{~V}$.

\section{Methodology for implementation of IntiWear}

This section presents the design, the photovoltaic PMMA fabrication and circuit development of IntiWear. This design incorporates luminescent concentrator of PMMA into a fashionable approach for self-power Wearables. Figure 1 shows the behavior of each piece in the harvesting system and a sketch of IntiWear Coat with these pieces attached. When sunlight strikes the LC of PMMA, excites the fluoropheres of the dye and produces a re-emission at low energies that is guided into the LC and collected by the pv-cells at the edges. (Figure 1C). The photocurrent generated by the pv-cell is proportional to the amount of concentrated light arriving over it.

\section{IntiWear's design}

In order to promote the use of fashionable accessories that harvest solar energy and hide electronics, we propose the use of different 
shapes and colors of PMMA that attaches solar cells. IntiWear's design uses two shapes of LC, isosceles triangles and squares. All of them obtained from laser cutting.

The following list presents different design factors that are considered into IntiWear

i. The solar cells are not exposed to sunlight directly in the garment. They are attached to the lateral side of the small LCs for both, maximize the energy absorption from the PMMA, and make the solar cell and electronics seamless.

ii. Each piece, $\mathrm{LC}+$ pv-cell, becomes a clothing adornment that could be sewed into textiles to provide a functional and fashionable solution. On-the-shelf solar cells of $2.2 \mathrm{~cm}$ by $0.7 \mathrm{~cm}$ are used in its design. The pieces are created from a 30 by $30 \mathrm{~cm}$ PMMA sheet with $0.6 \mathrm{~cm}$ of thickness by using a laser cutting technique. A hole is engraved in the PMMA piece to make the pv-cells fit by pressure.

iii. One of the most advantages using PMMA as energy concentrator is the larger possibilities of customizes the colors and shapes. The LC color depends of the dye and its concentration. IntiWear design used the PMMA doped with Lumogen F-Red305 at 100ppmm of concentration. This dye absorbs mainly between 300 and $620 \mathrm{~nm}$ and re-emit between 560 and $800 \mathrm{~nm}$. Because of this our first Intiwear prototype is decorated with much photovoltaic red adornment. However, other color could be chosen, each one with performance of concentration.

iv. The small size of the pieces could ergonomically be attached to the curvature of the body. Even that the PMMA and solar cells are rigid, they could be sewed to the garment with a specific gap in order to give some flexibility to the garment.

v. They could be connected in series and parallel in order to maximize the current generation.

vi. The pieces should be attached to the different clothing or accessories' surface that is exposed to sunlight such as a hat, shoulder and bag. In order to propose a fashionable style for the garments, a fashion designer collaborates in the model and fabrication of the applications.

\section{Characteristics of PMMA \& PV-cell for IntiWear}

In the IntiWear project, the dye selected was the Lumogen $\mathrm{F}$ Red305 - trademark produced by BASF. The amount of sunlight absorbed depends mostly of the dye absorption spectrum and its concentration. Someone could think to increase the sunlight absorption is just enough to increase the dye concentration but it can be counterproductive. Increasing the concentration also makes increase the self-absorption into the LC. ${ }^{33,41,42}$ Therefore, the optimum concentration must be established to generate the adequate photocurrent, since a concentrations smaller or larger to this value, generate minor photocurrent. The optimal concentration depends mainly of the geometrical dimensions of the LC and the chosen pvcell. ${ }^{4}$ The pv-cell used in IntiWear is the IXYS KXOB22-12X1, a little mono-crystalline Si-cell of dimensions $2.2 \mathrm{~cm} \times 0.7 \mathrm{~cm}$. According its manufacturer: efficiency $22 \%$, open circuit voltage $0.63 \mathrm{~V}$, short circuit current $50 \mathrm{~mA}$, voltage at power peak $0.50 \mathrm{~V}$, current at power peak $44.6 \mathrm{~mA}$, and fill factor $70 \%$ (Figure 4 ).

Considering the refraction indexes 1.49 and 1.00, for the PMMA and the air respectively, the $74 \%$ of the total internal reflection happens at incident angles higher than $42^{\circ}$ on the internal surfaces of the LC. Incident photons at minor angles do not remain totally confined. This defines a spatial region named loss-cone along which the fluorescence escapes out. In the most of cases the fluorescent emission is isotropic so the $26 \%$ of this is lost. ${ }^{4,43}$

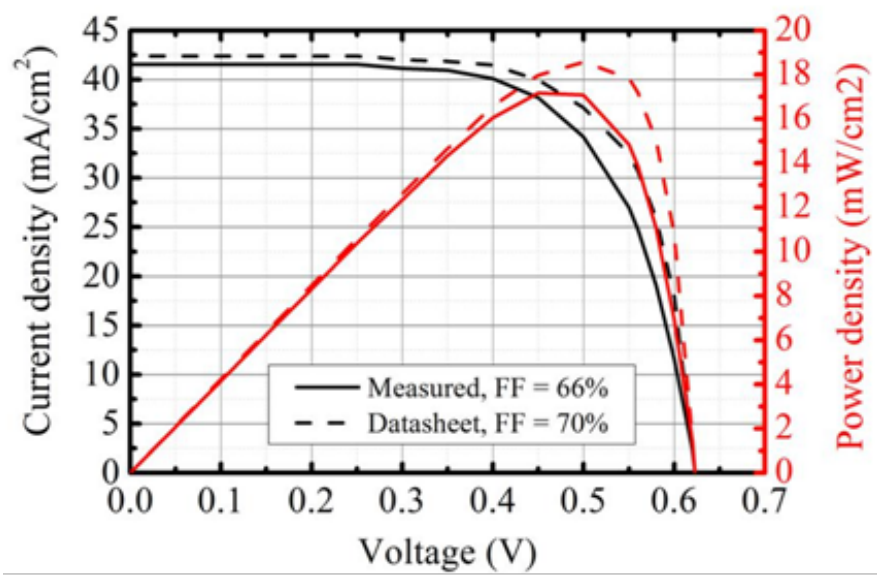

Figure 4 Electrical characteristics of micro pv-cell.

\section{Shapes photovoltaic \& PMMA}

IntiWear incorporates into textiles and accessories a photovoltaic based on LC of PMMA. The fabrication of these pieces should maximize the power generation without compromising wearability factors such as the body surface and curvature, user's movement and comfort, and a fashionable style. Thus, the minimum size with a maximum photocurrent is required. This project evaluates the triangle and square shapes to fit the pv-cell. However, PMMA gives the possibility to propose different shapes such as hexagons, circles and rectangles.

The shape and size of the LC selected for the IntiWear design is based on the estimations from a powerful simulation code made to simulate luminescent solar concentrator structures. The simulations have considered the photocurrent generated as function of the concentration of the dye and the number of edges covered by pvcells. ${ }^{44}$

We have evaluated different setups using LC and pv-cell ensembles. It is using triangle and square shapes. Figure $5 \mathrm{~A}$ shows the estimations of photocurrent versus dye-concentration for two setups of isosceles triangles, both using three pv-cells. The first is composed by three PMMA triangles, each one with an only edge covered by a pv-cell (Figure 5B), and the second composed by only one PMMA triangle with its three edges covered by pv-cells (Figure 5C). We see that the first option produces more energy than the second. It is an interesting result because the main cost of these devices is the pv-cells. In fact, the cost by square meter of the PMMA is negligible in comparison with the cost of the photovoltaic material.

We have also obtained estimations for setups of square of PMMA - all with four pv-cells. Figure 6A shows the results for three setups. The first composed by four squares of PMMA with only one pv-cell (Figure 6B), the second by two squares, each one with two edges photovoltaic cover (Figure 6C), and the third by an only square of PMMA with all edges covered. Also in these setups we see that the first option generates more photocurrent. 
A)

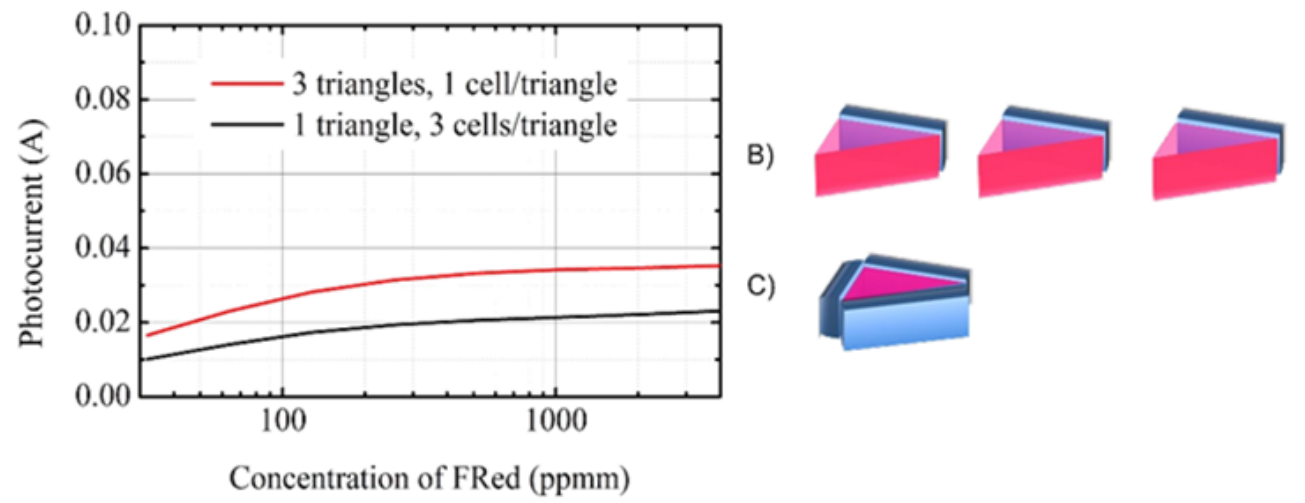

Figure 5 Photocurrent versus Concentration in the Triangle Setup. Each setup is composed by three pv-cells. For each piece: side-length $=2.2 \mathrm{~cm}$, thickness $=$ $0.6 \mathrm{~cm}$ and area $=2.09 \mathrm{~cm}^{2}$. A) Comparison of Photocurrent in each setup. B) 3 triangles, I cell/triangle. C) I triangle, 3 cells/triangle.

A)

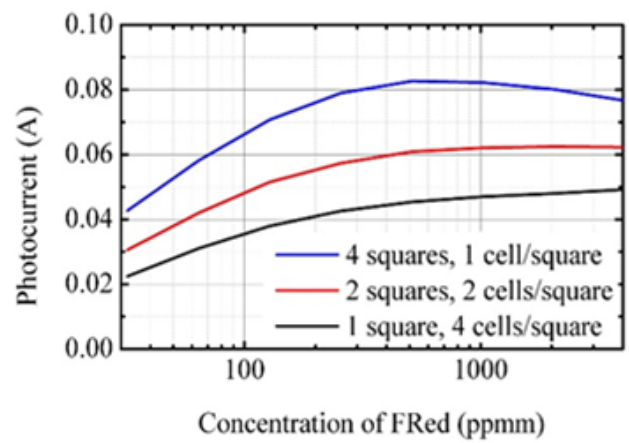

B)
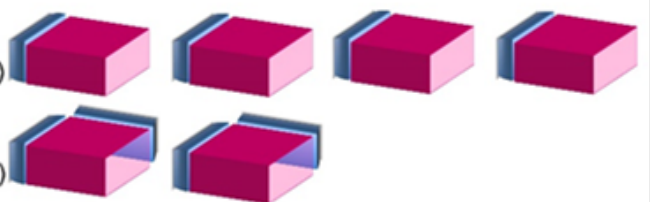

C)

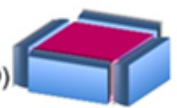

\section{D)}
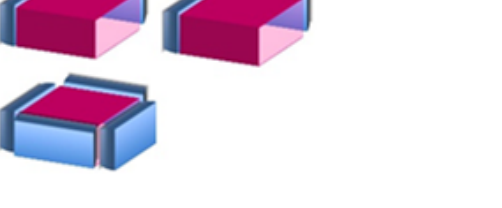

Figure 6 Photocurrent vs Setup of squares. Each setup is composed by four pv-cells. For each piece: side-length $=2.2 \mathrm{~cm}$, thickness $=0.6 \mathrm{~cm}$ and area $=4.84 \mathrm{~cm}{ }^{2}$. A) Comparison of Photocurrent in each setup. B) 4 squares, I cell/square. C) 2 squares, 2 cells/square. D) I square, 4 cell/square.

\section{Design of solar energy harvesting system}

The triangle and square setups are selected using the same number of pv-cells in order to compare the dye concentration for each setup. Even that each pv-cell is connected to a same area, the dye concentration in individual pv-cell is higher for both setups. For this application, the capacity required to supply of 3 Watts (W), responds to the need to charge a $1000 \mathrm{~mA}$ battery. The system losses are estimated at $30 \%$, so the efficiency $\left(\eta_{\text {system }}\right)$ is $70 \%$, and for this case. This design is considering that there will be a voltage drop given by the interconnection and that there will be losses because the solar radiation will not affect perpendicular to the pieces of the coat, and the pv-cell are attached to PMMA. The solar irradiance average was considered at $5 \mathrm{kWh} / \mathrm{m}^{2}$ per day (HSP), a low level considering the worst solar resource conditions. The Power of each pv-cell is $22.3 \mathrm{~mW}$ (Wp). Thus, from Equation 1, the required pv-cells $\left(N_{s c}\right)$ are 48pieces.

$$
N_{s c}=\frac{W}{W_{p} \cdot H S P \cdot \eta_{s y s t e m}}
$$

The system battery is $1000 \mathrm{~mA}$ at $3.7 \mathrm{~V}$. However, the control unit (charger system) requires a minimum of $4.5 \mathrm{~V}$ to perform a linear charge on the battery. The capacity of the battery can be higher, but the charging time will also be. Therefore, a battery with a capacity of $1000 \mathrm{~mA}$ is sufficient, to supply $35 \%$ of the total charge required by a standard cell phone.

Considering these conditions, is necessary a power photovoltaic system of $1000 \mathrm{~mW}$. For this system, the interconnection between pv- cells is required that provides $6 \mathrm{~V}$ and $178.4 \mathrm{~mA}$, which supposes a peak power of $1070 \mathrm{mWp}$, formed by four lines in parallel of $12 \mathrm{pv}$ cells in series with each one (Figure 7).

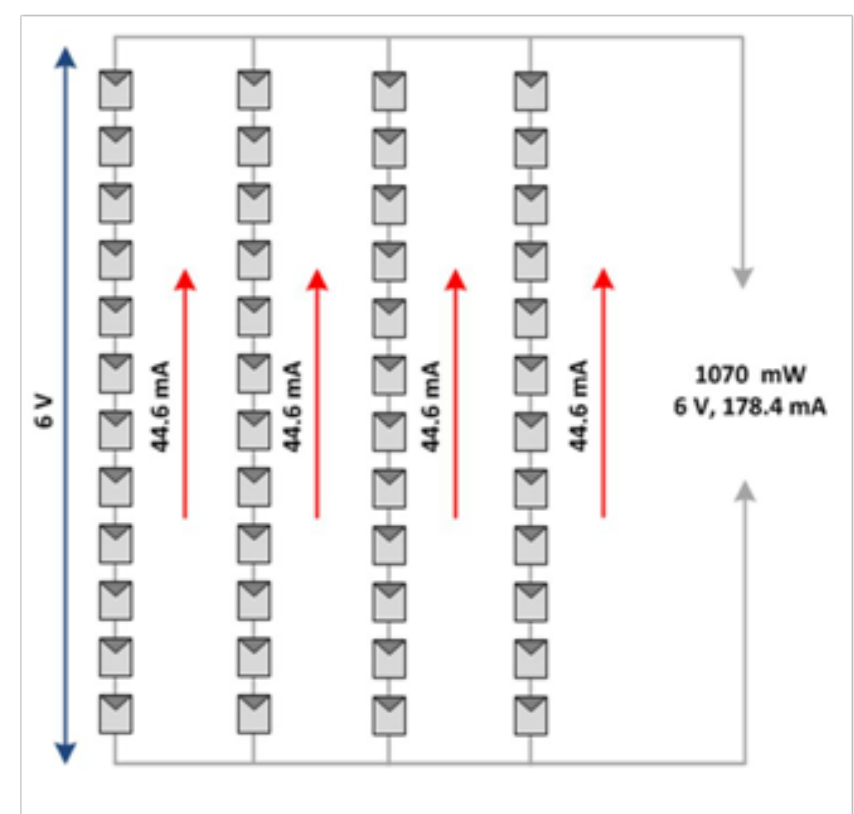

Figure 7 Interconnection of photovoltaic cells.

Finally, the real integration of the harvesters, control unit, energy storahe in the IntiWear shows in the Figure 8. 

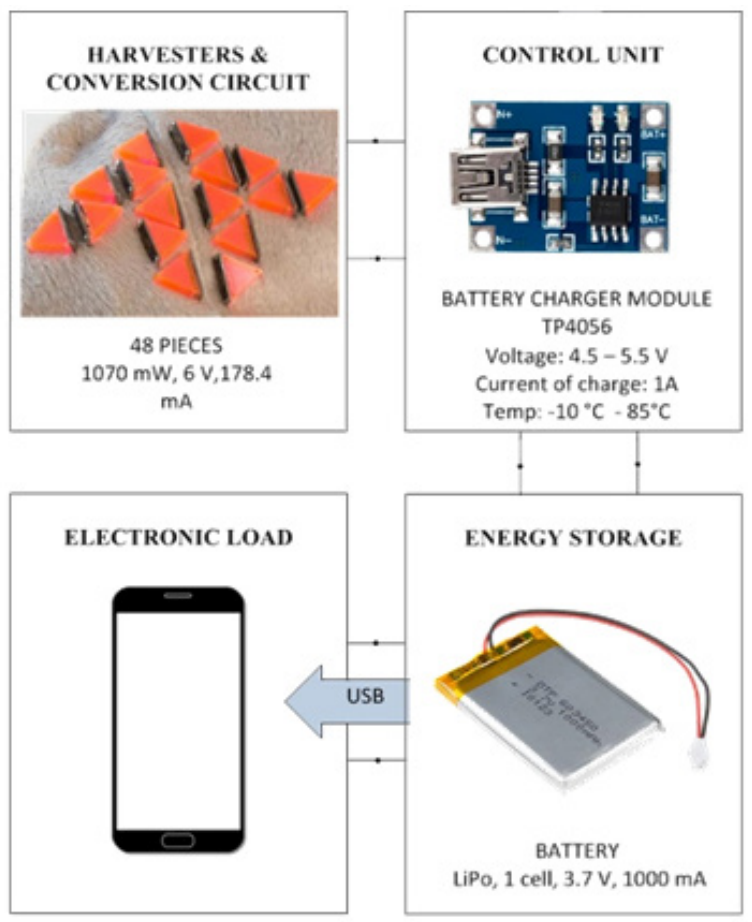

ENERGY STORAGE

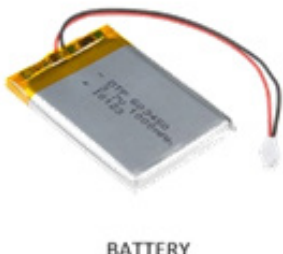

LiPo, 1 cell, $3.7 \mathrm{~V}, 1000 \mathrm{~mA}$

Figure 8 Integrated System of IntiWear

\section{Energy production}

To calculate the energy production $\left(\mathrm{E}_{\mathrm{D}}\right)$ it is necessary to know the installed peak power $\left(W_{P}\right)$, the average daily irradiance $\left(I_{a v g}\right)$ and the efficiency of the system $\left(\eta_{\text {system }}\right)$, as shown in Equation 2:

$$
E_{D}=W_{p} \cdot I_{\text {avg }} \cdot \eta_{\text {system }}
$$

From the calculation of the generated energy, it is estimated the load time $\left(T_{\text {load }}\right)$ that can be provided considering that a cell has an average consumption of $0.76 \mathrm{Wh}$ (Equation 3 ).

$$
T_{L O A D}=\frac{E_{D}}{0.76}
$$

A different quantity is the current density which is defined as the photocurrent generated by the LC divided by the top LC-surface area. Results for this quantity are shown in Figure 9 for the triangle and the square. Both shapes with only one edge are covered by one pv-cell. This figure shown that the current density of the triangle is bigger than of the square. For these shapes, the areas are 2.09 and $4.84 \mathrm{~cm}^{2}$ respectively.

Table I Energy production and percentage time charge with triangle shape

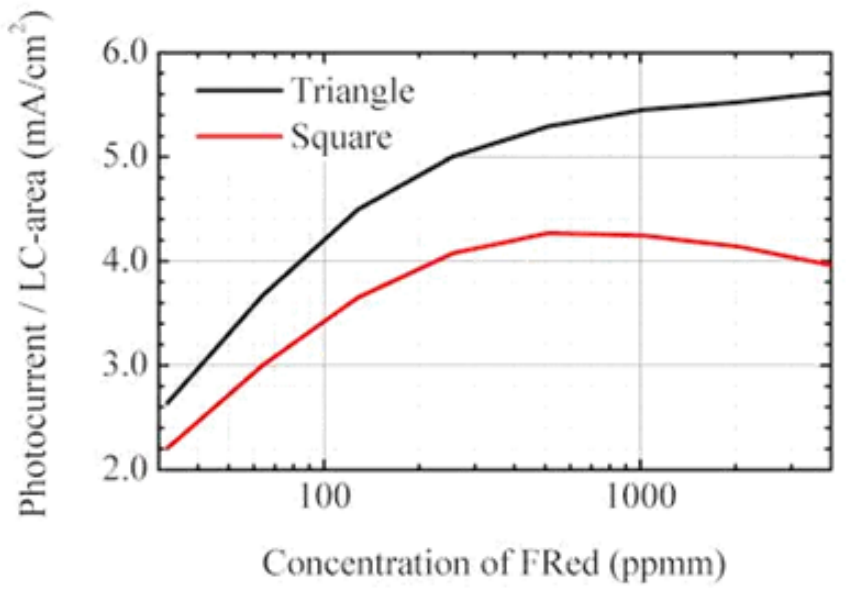

Figure 9 Photocurrent density with of pv-cell Side-length $=22 \mathrm{~mm}$

Due that the area in the square is bigger than triangle, the energy production is bigger. In the follow section shows the results about the both shapes.

\section{Discussions of results of IntiWear}

As for the energy process, the photovoltaic system was simulated for different levels of irradiance through the Lucas Nulle CO3208$1 \mathrm{~B}$ equipment that allows measuring the behavior of a solar cell at different inclination angles. This is important because the solar radiation is different in the year and it depends of the place. For example, in the coast, the solar radiation is attenuated by the water vapor in the atmosphere while in the mountain range the atmosphere is clearer. ${ }^{45}$

\section{Solar harvesting system test}

Assuming one hour of solar incidence, we calculated the energy produced by the system and estimated the load time that can provide the battery of $1000 \mathrm{~mA}$. For this system two types of geometry were considered, the triangle and the square, each of its sides measuring $2.2 \mathrm{~cm}$ length, or $2.09 \mathrm{~cm}^{2}$ and $4.84 \mathrm{~cm}^{2}$ respectively both geometric figures emphasize solar picking efficiencies, due to the absorption area. The triangle has a lower yield than the square, estimated at $30 \%$ and $20 \%$ respectively. Under these considerations, the load time was considered different levels of irradiance and assuming that the system was exposed to the sun all day. The results obtained, considering the triangle, are shown in Table 1. The percentage of load supplied is calculated assuming that a cell phone with $100 \%$ of the battery charged and a typical use has autonomy of 14 hours.

\begin{tabular}{llll}
\hline $\begin{array}{l}\text { Irradiance [kWh/ } \\
\mathbf{m}^{2} \text { day] }\end{array}$ & $\begin{array}{l}\text { Power generated by the Solar } \\
\text { Harvesting System [Wh/day] }\end{array}$ & $\begin{array}{l}\text { Loading Time } \\
{[\mathbf{h h : m m}]}\end{array}$ & $\begin{array}{l}\text { Loading Percent of the } \\
\text { I000mA Battery [\%] }\end{array}$ \\
\hline 3 & 2.247 & $2: 57$ & 21 \\
4 & 2.996 & $3: 56$ & 28 \\
5 & 3.747 & $4: 55$ & 35 \\
6 & 4.494 & $5: 54$ & 42 \\
7 & 5.245 & $6: 53$ & 49 \\
\hline
\end{tabular}

Also, the same procedure was performed considering the squares, whose performance is greater. In this case, the energy production is higher, and consequently the percentage of load supplied, is also higher. The results are shown in Table 2. 
Table 2 Energy production and percentage time charge with square shape

\begin{tabular}{llll}
\hline $\begin{array}{l}\text { Irradiance [kWh/ } \\
\mathbf{m}^{2} \text { day] }\end{array}$ & $\begin{array}{l}\text { Power generated by the Solar } \\
\text { Harvesting System [Wh/day] }\end{array}$ & $\begin{array}{l}\text { Loading Time } \\
\text { [hh:mm] }\end{array}$ & $\begin{array}{l}\text { Loading Percent of the } \\
\text { I000mA Battery [\%] }\end{array}$ \\
\hline 3 & 2.568 & $3: 22$ & 24 \\
4 & 3.424 & $4: 30$ & 32 \\
5 & 4.181 & $5: 37$ & 40 \\
6 & 5.136 & $6: 45$ & 48 \\
7 & 5.99 & $7: 53$ & 56 \\
\hline
\end{tabular}

Likewise, in the day the solar radiation is different at the morning, at noon and afternoon. Theses variations are influencing in the energy production and in the load time, and also, the people have some different activities in a day, therefore is possible that the exposure of the solar harvesting system to the sun will be less. Considering that a person may have an exposure to the sun for three hours, the simulations presented in different radiation levels (power density of the sun) are show in the Table 3.

Table 3 Energy production and time of charge with triangle shape

\begin{tabular}{lll}
\hline $\begin{array}{l}\text { Radiation in } 3 \\
\text { hours }\left[\mathrm{W} / \mathbf{m}^{2}\right]\end{array}$ & $\begin{array}{l}\text { Power generated by the Solar } \\
\text { Harvesting System [W/day] }\end{array}$ & $\begin{array}{l}\text { Loading Time } \\
{[\mathrm{hh:mm}]}\end{array}$ \\
\hline 1125 & 0.842 & $1: 06$ \\
1500 & 1.123 & $1: 28$ \\
1875 & 1.404 & $1: 50$ \\
2250 & 1.685 & $2: 13$ \\
2625 & 1.966 & $2: 35$ \\
\hline
\end{tabular}

The results obtained show that the load time in worst conditions of solar radiation is for one hour and for best conditions the time for supply energy is for two and half hours. Enough time for use a cell phone in case that her battery is discharged. Considering the use of square piece, the results are the show in the Table 4.

Table 4 Energy production and time of charge with square shape

\begin{tabular}{lll}
\hline $\begin{array}{l}\text { Radiation in } 3 \\
\text { hours }\left[\mathrm{W} / \mathbf{m}^{2}\right]\end{array}$ & $\begin{array}{l}\text { Power generated by the Solar } \\
\text { Harvesting System [W/day] }\end{array}$ & $\begin{array}{l}\text { Loading Time } \\
\text { [hh:mm] }\end{array}$ \\
\hline 1125 & 0.963 & $1: 16$ \\
1500 & 1.284 & $1: 41$ \\
1875 & 1.605 & $2: 06$ \\
2250 & 1.926 & $2: 32$ \\
2625 & 2.247 & $2: 57$ \\
\hline
\end{tabular}

Finally, the solar harvesting system has demonstrated that the energy generation for electronic devices with low consumption is possible, and the applications can be diverse. Shown below other applications of this system.

\section{Applications}

IntiWear could be applied to clothing and accessories. We present two different applications: a coat as power bank storage and a purse as a self-charging wearable.

\section{IntiWear coat}

IntiWear coat's design is a collaboration project with a Peruvian fashion designer. One of his requirements was to use equilateral 3D triangle-shape pieces. The minimum size of the triangle is related to the size of the pv-cell and they have been placed in the top of the shoulders of the coat (Figure 10A \& 10B) to ensure maximum exposure to the sun and for the design of the fashion designer. The length of the on-the-shelf pv-cell $(2.2 \mathrm{~cm})$ matches each triangle's side and the width of the pv-cell $(0.7 \mathrm{~cm})$ matches the triangle height. 48pv-cells are attached to PMMA pieces that are laser-cut in a triangle shape where 4 groups in parallel of 12 pieces in series are connected (Figure 6). The PMMA pieces with their pv-cells are placed in the external part of the coat. The connections have been realized inside the coat and covered by an insulted fabric.

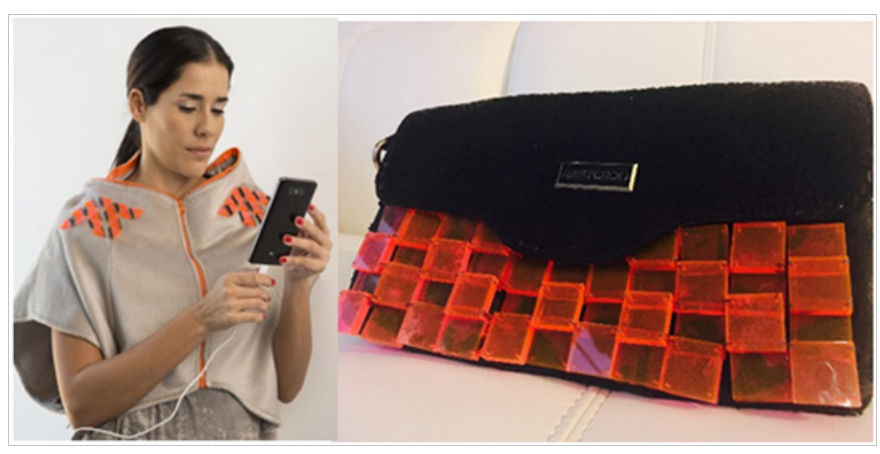

Figure 10 IntiWear applications. A) Coat for charging a phone. B) IntiWear Purse as a self-charging wearable.

The pieces were attached in an alpaca (soft and silky natural fiber) fabric. The main motivation to use this fabric is our inspiration in Peruvian farmers. Their usual working journey goes from 6AM to 4PM. They are usually exposed to the sun during that period of time and many of them do not have electricity at home. Alpaca is fabric very common in the Peruvian culture. Also, for our design, alpaca's low-density facilitates that the connectors easily go through it. Due to the pv-cells are close to a curved area that is the shoulders, the gap between each piece is $0.25 \mathrm{~cm}$ in order to give flexibility to the garment. We compare a sample of 5 different fabrics with an attached pv-cell + PMMA. The selection of the fabric color is done regarding to the one that presents the higher PMMA concentration. Due to the harvesting system will require a certain number of pv-cells, the Fashion Designer lead the distribution of the cells in the coat. They were installed in the front and the back of the coat and close to the shoulder's area as it is more exposed to the sun. They were distributed with 24 in the front and 24 in the back of the coat.IntiWear Coat generates $4.6 \mathrm{~V}$ and could power different devices that operate at 3.7 $\mathrm{V}$ such as a Smartphone. In optimal conditions that IntiWear Coat exposed to sunlight for 3 hours could supply energy for 2.35 hours.

\section{IntiWear Purse}

Figure 10B shows IntiWear Purse. It is an accessory that 
incorporates IntiWear's concept. The aim of this application is to use an accessory instead of clothing to a self-charging device instead of a power bank. It also uses the on-the-shelf pv-cell $(2.2$ by $0.7 \mathrm{~cm})$. This purse include 48 PMMA squares photovoltaic PMMA on it, an option for self-charging devices. This wearable uses the button of the purse as a switch to turn on an LED whenever the purse is opened. The electronic components that are used in the prototype includes the following consumption: an Ultra low power microcontroller (Adafruit Gemma) that draws $9 \mathrm{~mA}$ while running, $20 \mathrm{~mA}$ for an input pin, $20 \mathrm{~mA}$ for an output pin, one high power LED at $17 \mathrm{~mA}$ and a TP4056 Module at $5 \mathrm{~mA}$. Total up to $71 \mathrm{~mA}$ of current draw. A Lithium Ion Polymer Battery of $3.7 \mathrm{~V}, 100 \mathrm{mAh}$ is used. IntiWear Purse could operate with this battery for 1.41 hours in full usage and its capacity requires a supply of 0.26 Watts. The TP4056 Module regulates the photocurrent from the photovoltaic PMMA pieces and could charge $5 \mathrm{~V}$ battery. In optimal conditional, IntiWear Purse could recharge the lithium battery for 2 hours and 57 minutes.

\section{Conclusion}

The IntiWear's concept that has been designed and implemented could be one of the many solutions for solving issues in Wearables Technologies in order to give a new dimension to self-sufficient devices. Our approach merges a novel material (PMMA) into fashion technology to generate energy for Wearables. It aims to reduce greenhouse gas to charge small electronic devices as self-sufficient devices will reduce the energy consumption of individual. The results presented here shows that it is possible to integrate PMMA as a solar concentrator with solar cell to store energy into a battery that then will charge an electronic device.

Fashion designers are already using this type of acrylic into their design; however, the added value in this prototype is the energy storage into Wearable. Now, the body surface can be used as energy storage as greater surface area of sunlight will have a greater yield in energy production. Two prototypes were designed: a coat for charging a Smartphone and self-charing wearable (purse). The prototypes were created in collaboration with a Peruvian fashion designer. The design is taking into consideration the small size of the pv-cells to maximize the energy productionusing the body shape of the person. Different setups evaluates the possibilities of minimize quantity of pv-cells used in the system and maximize the energy harvesting. Thus, the cost of the device could be reduced (PMMA is much cheaper than pvcells). We compare the use of 4 pv-cells in 4, 2 and 1 squares and the use of 3 pv-cells in 3 and 1 triangle. We have seen that the estimations of photocurrent versus the dye-concentration that using only one pv-cell in one edge produces much more energy than have two or more pv-cells into a PMMA shape.We have demonstrated that with 48 photovoltaic PMMA pieces in a triangle shape we could supply $35 \%$ of battery's capacity in 5 hours, and with 48 photovoltaic PMMA pieces in a square shape, $32 \%$ of the battery's capacity in 4 hours. Spring and summer time are the best period of the year to use this device as sunlight is stronger and daylight is longer.

The IntiWear's design concept has been developing as a pilot and further work has to be done to improve the entire system such as:

a. Analyzing different color spectrum of the PMMA to play with the color meanwhile doing a fashion design to ensure the minimum energy for the Wearable application.

b. Multilayer design and test to improve the yield of the energy conversion and radiation. c. Check the absorption area of different design shapes.

d. Work on other type of garments such as sunglasses, hats and jewelry that could lead to different applications. However, these kinds of garments might lead to study a new setup for smaller surfaces.

e. Novel garments for the summer collections are going to be designed with the Fashion Designer.

\section{Acknowledgements}

None.

\section{Conflict of interest}

Author declares there is no conflict of interest in publishing the article.

\section{References}

1. CCS Insight. 2016. Wearables market to be worth 25 dollars billion by 2019. 2016.

2. Liu X, Vega K, Maes P, et al. Wearability factors for skin interfaces In Proceedings of the 7th Augmented Human International Conference 2016. ACM; 2016.

3. Paradiso JA, Starner T. Energy scavenging for mobile and wireless electronics. IEEE Pervasive computing. 2005;4(1):18-27.

4. Daorta SF, Proto A, Fusco R, et al. Cascade luminescent solar concentrators. Applied Physics Letters. 2014;104(15):153901.

5. Sandra Filipa Henriques Correia. Organic-inorganic hybrid materials for green photonics: luminescent solar concentrators. 2017.

6. Khalifa S, Hassan M, Seneviratne A, et al. Energy-harvesting wearables for activity-aware services. IEEE Internet Computing. 2015;19(5):8-16.

7. Beeby SP, Tudor MJ, NM White. Energy harvesting vibration sources for microsystems applications. Measurement science and technology. 2006;17(12):R175.

8. Kim SJ, We JH, Cho BJ. A wearable thermoelectric generator fabricated on a glass fabric. Energy \& Environmental Science. 2014;7(6):19591965 .

9. Masotti D, Costanzo A, Adami S. Design and realization of a wearable multi-frequency RF energy harvesting system. Proceedings of the 5th European Conference on Antennas and Propagation (EUCAP). 2011:517-520.

10. Nathan A, Ahnood A, Cole MT, et al. Flexible electronics: the next ubiquitous platform. Proc IEEE 100, Special Centennial Issue. 2012:1486-1517.

11. Roselli L, Carvalho NB, Alimenti F, et al. Smart surfaces: Large area electronics systems for Internet of Things enabled by energy harvesting. Proc IEEE. 2014;102(11):1723-1746

12. Stoppa M, Chiolerio A. Wearable electronics and smart textiles: a critical review. Sensors (Basel). 2014;14(7):11957-11992.

13. Song Z, Wang X, Lv C, et al. Kirigami-based stretchable lithium-ion batteries. Scientific reports. 2015;5:10988.

14. Jia W, Wang X, Imani S, et al. Wearable textile biofuel cells for powering electronics. Journal of Materials Chemistry. 2014;(43):8184-18189.

15. Julien $G$ Noel. Review of the properties of gold material for MEMS membrane applications. IET Circuits, Devices \& Systems. 2016;10(2):156-161. 
16. Ostfeld AE, Gaikwad AM, Khan Y, et al. High-performance flexible energy storage and harvesting system for wearable electronics. Scientific reports. 2016.

17. El-Kady MF, Kaner RB. Scalable fabrication of high-power graphene micro-supercapacitors for flexible and on-chip energy storage. Nature communications. 2013;4:1475.

18. Yuan L, Lu XH, Xiao X, et al. Flexible solid-state supercapacitors based on carbon nanoparticles $/ \mathrm{MnO}_{2}$ nanorods hybrid structure. ACS nano. 2011;6(1):656-661.

19. Lee YH, Kim JS, Noh J, et al. Wearable textile battery rechargeable by solar energy. Nano letters. 2013;13(11):5753-5761.

20. Huang J, Badam A, Chandra R, et al. WearDrive: Fast and EnergyEfficient Storage for Wearables. USENIX Annual Technical Conference. 2015:613-625.

21. Pu X, Li L, Song H, et al. A self-charging power unit by integration of a textile triboelectricnanogenerator and a flexible lithium-ion battery for wearable electronics. Advanced Materials. 2015;27(15):2472-2478.

22. Paul D Mitcheson. Energy harvesting for human wearable and implantable bio-sensors. 2010 Annual International Conference of the IEEE Engineering in Medicine and Biology. 2010:3432-3436.

23. Thad Starner, Joseph A Paradiso. Human generated power for mobile electronics. Low power electronics design. 2004;45:1-35.

24. Ramsay MJ, Clark WW. Piezoelectric energy harvesting for bio MEMS applications. In Proc SPIE. 2001;4332:429-438.

25. Raghunathan V, Kansal A, Hsu J, et al. Design considerations for solar energy harvesting wireless embedded systems. IPSN 2005. Fourth International Symposium on Information Processing in Sensor Networks, 2005. 2005: 64 p.

26. Zhang N, Chen J, Huang Y, et al. A wearable all-solid photovoltaic textile. Advanced Materials. 2016;28(2):263-269.

27. Zhang Z, Guo K, Li Y, et al. Acolour-tunable, weavablefibre-shaped polymer light-emitting electrochemical cell. Nature Photonics. 2015;9(4):233-238.

28. Gang Li, Rui Zhu, Yang Yang. Polymer solar cells. Nature photonics. 2012;6(3):153-161.

29. Smelik A, Toussaint L, Dongen PV. Solar fashion: An embodied approach to wearable technology. International Journal of Fashion Studies. 2016;3(2):287-303.

30. Pvilion. Tommy Hilfiger Solar Clothing. 2014.
31. Ecouterre. Lux Solar-Panel Necklace Lights Up Any Outfit. 2009.

32. Landerer D, Bahro D, Röhm H, et al. Solar Glasses: A Case Study on Semitransparent Organic Solar Cells for Self-Powered, Smart Wearable Devices. Energy Technology. 2017; 5(11):1936-1945.

33. Kaysir MR, Fleming S, Argyros A. Modeling of stimulated emission based luminescent solar concentrators. Opt Express. 2016;24(26):A1546A1559.

34. Zhang Y, Sun S, Kang R, et al. Polymethylmethacrylate-based luminescent solar concentrators with bottom-mounted solar cells. Energy Conversion and Management. 2015;95:187-192.

35. Debije MG, Paul PC Verbunt. ThirtyYears of Luminescent Solar Concentrator Research: Solar Energy for the Built Environment. Advanced Energy Materials. 2012;2(1):12-35.

36. Weber WH, Lambe J. Luminescent greenhouse collector for solar radiation. Appl Opt. 1976;15(10):2299-2300.

37. Levitt JA, Weber WH. Materials for luminescent greenhouse solar collectors. Appl Opt. 1977;16(10):2684-2689.

38. Verbunt PPC, Debije MG. Progress in luminescent solar concentrator research: solar energy for the built environment. World Renewable Energy Congress-Sweden. 2011:2751-2758.

39. NanJing TopPower ASIC. TP4056, 1A Standalone Linear Li-Ion Battery charger with thermal regulation in SOP-8.

40. LiPo battery CL523450.

41. Drake JM, Lesiecki ML, Sansregret J, et al. Organic dyes in PMMA in a planar luminescent solar collector: a performance evaluation. Appl Opt. 1982;21(16):2945-2952.

42. Dienel T, Bauer C, Dolamic I, et al. Spectral-based analysis of thin film luminescent solar concentrators. Solar Energy. 2010;84(8):1366-1369.

43. Fusco R, Liscidini M, Sthy Warren Flores Daorta, et al. Light concentration device. 2014

44. Sahin D, Ilan B, Kelley DF. Monte-Carlo simulations of light propagation in luminescent solar concentrators based on semiconductor nanoparticles. Journal of Applied Physics. 2011;110(3):033108.

45. Gutiérrez-Trashorras AJ, Villicaña-Ortiz E, Álvarez-Álvarez E, et al. Attenuation processes of solar radiation. Application to the quantification of direct and diffuse solar irradiances on horizontal surfaces in Mexico by means of an overall atmospheric transmittance. Renewable and Sustainable Energy Reviews. 2018;81:93-106. 